\title{
Emotional expression of students and the pedagogical process
}

\author{
Venera Minazova ${ }^{1 *}$, Nadezhda Rachkovskaya ${ }^{2}$, Veronika Efimenko $^{3}$ and Sovbika \\ Bashaeva $^{4}$ \\ ${ }^{1}$ Chechen State University, 364024 Grozny, Russia \\ ${ }^{2}$ Moscow Region State University, 141014 Mytishi, Russia \\ ${ }^{3}$ Kamchatka State University named after Vitus Bering, 683032 Petropavlovsk- \\ Kamchatskiy, Russia \\ ${ }^{4}$ Chechen State Pedagogical University, 364045 Grozny, Russia
}

\begin{abstract}
This article discusses the need for adequate perception and interpretation of emotional states and expressions of students in the process of pedagogical interaction. The connection has been found between the emotional expression of students and their ethnic, social and cultural identities. Based on the research findings of the emotional space of the population in the Russian Far East (Kamchatka territory and Magadan region), the authors demonstrate the specifics of emotional states of students, conditioned by the harsh climate and extreme living conditions, including seismic activity, permafrost and other. The article suggests the ways of forming teachers' professional skills and knowledge, necessary for a successful professional career in ethnically diverse regions with a high level of natural and technological risks. These include such as: special courses as part of the general curriculum, attending national celebrations, local history museums, familiarity with folklore, decorative and applied arts, which objectify ethnic mentality. This will increase the level of competences of teachers in interpreting emotional states and expressions of teachers.
\end{abstract}

Humanist development of pedagogy identifies new directions for scientific research, attracts attention to understudied issues within education, including the emotional lives of students. The issues of emotional development of children, integration of emotional and rational ways of learning, the influence of emotions onto intellectual processes, ensuring emotional wellbeing of children at school, development and correction of emotional identity - these are the issues widely discussed within humanist theories and person centered approaches $[1 ; 2 ; 3]$.

It is widely acknowledged that emotions play an integral role in pedagogic processes as well. This makes it vital for education specialists to know more about the emotional lives of students, take them into consideration as part of their professional activity and support the comprehensive development of children's emotional space. $[4 ; 5 ; 6]$.

\footnotetext{
* Corresponding author: veneraminazova@mail.ru
} 
The humanist approach that replaced technocratic one resulted in humanity acknowledging the meaning of emotions in lives, development and strengthening the identity. Previously many scholars have been focusing on studying the cognitive processes, while the last decade shows peaked interest to emotional aspects of the mental lives of people.

Emotion is a complex category, which makes it interdisciplinary. As a result, it becomes a subject for research for such disciplines as philosophy, psychology, physiology, pedagogy. In addition, as emotional reactions are an inalienable part of human beings, they are being studied by social sciences, political science, sociology, ethnology and other. At the intersection of different scientific directions relatively new approaches emerge and actively develop, such as cross-cultural psychology, for example [7;8].

The majority of intercultural psychological researches are based on perceptions of peculiarities of systems of thought, behaviors, emotional states of representatives of diverse cultures. "Any historically formed collective - a nation, a class, a union, a city, a town perceives, imagines, assesses, loves and hates the existing reality, the living conditions, the being in their own way. Through this attitude to everything that objectively exists, they express their "spirit", or "soul", or "character" [9, p. 479].

The culture forms special patterns of emotional space of people, which demonstrated by the T.Schwartz's research. According to him, the culture impacts the development of affective and cognitive elements of mentality, its ability to differentiate and identify living experience, peculiar ways of gaining experience. Each psychologic process that takes place when people interact with their environment, has its own place and functions in a general structure of people's adapting to their realities [10, p. 105].

Modern pedagogic theory and practice are based on intercultural research, as teacher interacts with representatives of different social strata, cultures, nations, ethnic groups, and mentalities. According to P. Ekman, "each culture possesses its own rules of expressing emotions and if one breaks these rules there might be minor or major consequences for an individual. These cultural rules may demand to suppress or disguising certain emotions, and frequent expression of others" [11, p.84; 12].

Thus, representatives of eastern cevilisation, for expamle, Chinese should be smiling when talking of a death of a close relative. Japanese are also supposed to be withheld at the moment of sorrow or grief, according to their tradition. Western society vice versa, allows freedom in expressing negative emotions. Moreover, the culture of Eastern Europe in a certain situation, not just suggest that there are no limitations in expressing sorrow or grief, but also demands expression of these emotions. Thus, burial tradition in Russia includes includes a number of procedures (washing a dead man's body, mourners, etc.), which create a mood for all the visitors - sorrow, loss, grief - and bring to the surface emotions. Having children at these events is not prohibited, and is even encourages, as there is an opinion that children should be exposed to feelings of pity, sorrow, loss, so that they do not grow up selfish and are able to value happiness.

Traditions of some ethnic groups do not just harshly regulate the emotional lives of people, but also taboo any expressions of emotions. One of the examples might be a tribe of collectors and hunters from forests of Malaysia. People from this tribe never talk about their feelings, and "do not differentiate between 'feelings' and 'thoughts', and they have many rules that regulate and suppress emotions. In the process of upbringing their children, they pay special attention to feelings of fear and being shy, while human behavior is described through rules, that people should observe" [8, p. 120-121].

Emotional lives of some nations are characterized by a traditional prevalence of positive or negative feelings. As Europeans grow up they have certain ideas about "cheerful" peoples: Italians, Greeks and peoples with a "Nordic" temper: the British, Germans, Finns, Swedes. These stereotypes are also reconfirmed by scientific research. Often, when 
studying emotions that are most prevalent for a particular nation, researchers first turn to the national dictionary describing the emotional space. Because having "... a term, a normative "label" that denotes a certain feeling contributes to both its understanding and the development of certain behavioral syndromes" [8, p.112]. A comparative analysis of the dictionaries of emotions shows that the same emotional states are "re-recognized" by some peoples (the emotional dictionary is marked by a large number of names that convey different shades of emotions), while other nations, on the contrary, are "unrecognized" (meager emotional vocabulary). Compared to Europeans, Tahitians, for example, "rerealize" the state of anger, shame and fear, and "underestimate" feelings of loneliness, depression, and guilt. According to I.S. Kon, there are significant cultural differences in understanding and the level of the acuteness of the experience of shame and guilt, loneliness, depression. So, in Africa, depression is much less common than in England, and Africans do not go through depression as often and as painful as Europeans [8].

The aforesaid applies to the indigenous ethnic groups inhabiting the Russian Far East. The Far East is a unique multinational region, significantly remote from the federal center. The territory of the Far East is inhabited by various ethnic groups: Koryak, Itelmens, Chukchi, Evens, Eskimos, Nenets, Dolgans, Yukagirs and other indigenous peoples, as well as visitors - representatives of other nationalities and nationalities of Russia who came here at different times. This region, rich in minerals and natural resources, has created a unique society with its unique multiethnic and multicultural environment.

The indigenous peoples of the Far East of Russia have a cheerful disposition - the Koryaks, Itelmens, Chukchi are very emotional. The famous biologist and traveler G.V. Steller, who visited Kamchatka in the 18th century, drew attention to the fact that "Koryaks speak their language unusually loud, accompanying their speech with noise and screaming" [13, p. 15], "their barbaric dances are in line with their wild screaming. As soon as they begin, they are already so frantic that sweat pours from them in streams» [13, p. 61]. Emotionality is also manifested in the dances of other Kamchatka peoples. At Itelmen festivals, it is customary to perform a "dance in which all men hide in the corners ... one of them jumps forward and starts furiously pounding his chest, hips, clapping, waving his hands overhead, spinning around" [13, p. 61], and some dances by Itelmens last from 12 to 15 hours, starting in the evening and to the very morning.

The harsh nature of the North makes people emotional and allows them experiencing predominantly positive emotions: the Koryaks "have fun with carefree joy, and sometimes when their house is covered with snow, they have to have fun until they clear the way out" $[14$, p. 26]. In addition, the tendency to experience positive emotions, apparently, is a kind of psychological antidepressant.

The Itelmen have a particularly well-developed sense of humor: "the first thing they do, when there is a newcomer in Kamchatka, they give him or her a nickname in their own language, based on one or another personal feature of a newcomer" [13, p. 62]. According to G.V. Steller, particular attention should be paid to itelmen comedies, "the themes of which are either the new customs and customs of the natives, or the comic situations, words and adventures of the Kamchadals themselves" [13, p. 62], also "... Itelmen like to tell each other different comedic and blasphemous stories about Kutha" [13, p. 63].

As V. Voigt notes, "The Itelman does not know shame; gratitude is also not in his character. He responds to gentle treatment with rudeness and insolence "[14, p. 47]. Itelmen do not even feel reverential feelings towards their god Kuthu, they do not consider him worthy of respect, never turn to him with requests and do not thank him. This is how representatives of European culture, such as V. Voight, understand the customs and behaviors of Itelmens. This interpretation is based on the alien's point of view and it does not dive into the mentality, culture of the indigenous people of Kamchatka. Providing mutual assistance, providing each other with various kinds of services is an integral 
attribute of the Itelmen relationship system. This type of interpersonal relations has been developing and fixed among Itelmens for centuries, which was facilitated by the harsh natural conditions of life. Self-evident mutual assistance has long passed into the sphere of the unconscious and has become a part of the mentality of the Itelmen people, which leads to an incorrect interpretation of the personal qualities of Itelmens by representatives of alien European culture.

In addition to ethnicity, the specifics of people's emotional space are determined by regional characteristics. A region is not just an administrative system, but a specific community of people, distinguished by the unity of economic, political and spiritual life. The region is a unique space of human socialization, in which the formation, preservation and transmission of cultural norms and values to the younger generations take place. The Kamchatka Territory today, as you know, belongs to the regions of Russia, especially prone to natural and technological hazards. As E.V. Friedman notes, natural and man-made disasters create extreme conditions for the life of Kamchatka. This is expressed in the constant threat of earthquakes, tsunamis, prolonged winters, heavy snowfalls, environmental pollution, as well as interruptions in the supply of electricity and heat to the region.

These phenomena, of course, create psychological stress [15] among the population of the peninsula, including determining the peculiarities of the Kamchatka's emotional life. People living in extreme conditions are especially often in a state of stress, experiencing panic moods, feelings of danger, insecurity, anxiety, fear, as well as other negative emotions and feelings. E.V. Friedman states that "Among all respondents (420 people), one in six $(17 \%)$ is afraid of earthquakes, one in twelve $(7.8 \%)$ defines their attitude to this phenomenon in Kamchatka as panic, every third (37.5\%) is worried about the possibility of a strong earthquake "[ $[16$, p. 20]. This state of affairs is largely created by rumors about the upcoming catastrophic earthquake on the peninsula with an exact determination of the date, strength and size of the destruction. Given that these rumors arise in Kamchatka at intervals of 2-3 times a year, and then are actively discussed in the families of the inhabitants of the peninsula, it is not difficult to assume what is the emotional mood of children, who attend school at this time.

The influence of the factor of regionalization of education can also be illustrated by the example of the Magadan region, which is located in the north-east of the Russian Federation, and belongs to the Far North. The region is characterized by extreme living conditions with permafrost and unique natural resources. Intensive gold mining led to a dangerous concentration of compounds of lead, iron, copper and manganese in the Kolyma, Tenka and Omchak rivers. In addition, large foci of mercury infection were recorded in the region. The harsh climate, environmental problems and vitamin deficiency negatively affect the psycho-emotional state of children and adolescents, which in turn can cause deviant behavior and even crimes.

All this should be acknowledged and taken into account in their activities by public education workers, especially teachers, as they meet and communicate with children on a daily basis. Awareness of teachers about the peculiarities of the emotional life of schoolchildren will undoubtedly contribute to the establishment of a favorable psychological climate in the school team. It will result in an improvement of the teacherstudent relationship, and if the teacher is interested, it will create a favorable emotional background for teaching and upbringing.

An integral part of the pedagogical skill of the teacher is the ability to correctly interpret the emotions of students and to correctly identify the reason for a certain emotional state. $[17 ; 18 ; 19 ; 20]$. For example, pranks by the Koryak and Itelmen students are mostly attributed not to maliciousness, but to the specificity of mentality. While bad mood, the predominance of negative emotions and, consequently, the passivity of the students, the 
state of boredom and the lack of desire to work during class may be caused by a rumor about an upcoming earthquake or bad weather.

Moreover, a teacher's behavior must correspond to the ethnical specificity of the emotional expressions of students. For example, an overly strict and distant teacher is at risk of being not understood and, consequently, not accepted by students. However, excessive emotional lability might disorganize the learning process. Thus, it is important for teachers to know the limits, when expressing emotions. Such nuances of pedagogical work in an ethnical environment must be noted during professional training for teachers at the Far East universities.

\section{References}

1. A. Ortony, G.L. Glore, A. Collins, The Cognitive Structure of Emotions (Cambridge, 1995)

2. K.T. Schtrogman, The Psychology of Emotion (London, 1973)

3. P.M. Yakobson, Feelings, Development and Education (Knowledge, Moscow, 1976)

4. K. Flake-Hobson, Child Development and Relationships: Translation from English (Center for Human Values, Moscow, 1993)

5. D. Shaffer, Developmental Psychology: Childhood \& Adolescence (Piter, Saint Petersburg, 2003)

6. G.I. Shukina, The Problem of Cognitive Interest in Pedagogy (Pedagogy, Moscow, 1971)

7. M. Mid, Culture and the World of Childhood (Science, Moscow, 1988)

8. I.S. Kon, Child and Society: (Historical and Ethnographic Perspective) (Science, Moscow, 1988)

9. G.G. Shpet, Introduction to Ethnic Psychology (Works, Moscow)

10. S.V. Lurie, Historical Ethnology: Textbook. Manual for universities (Moscow, 1997)

11. Ekman P. Emotion in the Human Face. - (Cambridge University Press, New York, 1986)

12. C.E. Izard, The face of emotion (Appleton-Century-Crofts, New York, 1971)

13. G.V. Steller, From Kamchatka to America (Publishing house "P.P. Soikin", Leningrad, 1927)

14. V. Woit, Kamchatka and its inhabitants (Printing house of Saint Petersburg city police, Saint Petersburg, 1855)

15. J.A. Gray, The Psychology of Fear and Stress (New York, 1971)

16. E.V. Fridman, Conditions and Factors for Managing a Region with a High Natural and Technological Risk (Moscow, 1999)

17. D. Goleman, Emotional intelligence (Bantam books, New York, 1995)

18. J.D. Mayer, P. Salovey, Emotional development and emotional intelligence: Educational implications (Basic Books, New York, 1997)

19. D.D. Dill, What teachers need to know. The knowledge, skills, and values essential to good teaching. and Associates (Jossey-Bass Publishers, San Francisco)

20. K. Gebauer, Turbulenzen im Klassenzimmer: emotionales Lernen in der Schule (Klett-Cotta, Stuttgart, 1997) 